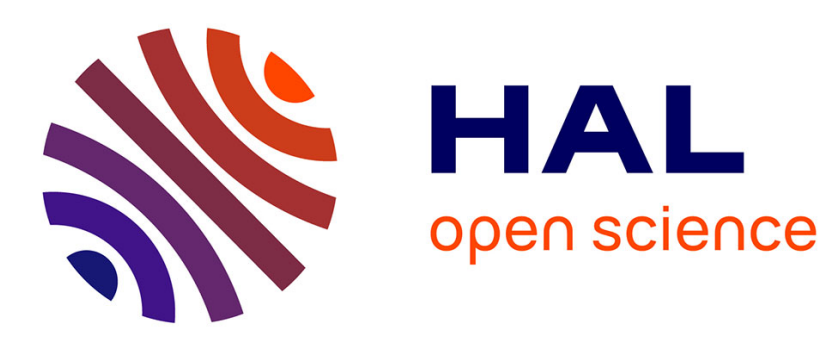

\title{
Comptes Rendus des exposés présentés au Colloque de Microscopie Electronique à Balayage 73 LYON, 21 et 22 juin 1973 \\ G. Fontaine, J. Philibert
}

\section{- To cite this version:}

G. Fontaine, J. Philibert. Comptes Rendus des exposés présentés au Colloque de Microscopie Electronique à Balayage 73 LYON, 21 et 22 juin 1973. Revue de Physique Appliquée, 1974, 9 (2), pp.341-341. 10.1051/rphysap:0197400902034100 . jpa-00243784

\section{HAL Id: jpa-00243784 \\ https://hal.science/jpa-00243784}

Submitted on 1 Jan 1974

HAL is a multi-disciplinary open access archive for the deposit and dissemination of scientific research documents, whether they are published or not. The documents may come from teaching and research institutions in France or abroad, or from public or private research centers.
L'archive ouverte pluridisciplinaire HAL, est destinée au dépôt et à la diffusion de documents scientifiques de niveau recherche, publiés ou non, émanant des établissements d'enseignement et de recherche français ou étrangers, des laboratoires publics ou privés. 


\title{
REVUE DE PHYSIQUE APPLIQUÉE
}

Supplément au "Journal de Physique "

\section{Comptes Rendus des Exposés}

\author{
Présentés au
}

\section{Colloque}

\section{de Microscopie Electronique à Balayage 73}

\section{LYON, 21 et 22 juin 1973}

\section{AVANT-PROPOS}

L'ensemble des articles qui suivent constitue le compte rendu du Colloque de Microscopie Electronique à Balayage qui s'est tenu à Lyon les 21 et 22 juin 1973. Au cours des dernières années, cette technique s'est fortement développée et le colloque était limité à un aspect de la question : l'étude quantitative des contrastes observés. Ce colloque faisait suite à des réunions informelles qui s'étaient tenues les années précédentes à Bellevue et à Lyon, son organisation et notamment l'invitation de nos collègues étrangers fut rendue possible grâce au concours du C. N. R. S. dont la RCP n ${ }^{0} 267$ « Microscopie Electronique à Balayage Quantitative» a pour but de favoriser ce type de réunions. Tous les articles ne nous sont malheureusement pas parvenus à temps mais nous n'avons pas estimé possible de différer davantage la publication dont nous remercions la Revue de Physique Appliquée.

\section{G. Fontaine, J. Philibert.}

